\title{
Acetone Sensing and Catalytic Conversion by Pd-Loaded $\mathrm{SnO}_{2}$
}

\author{
Pascal M. Gschwend ${ }^{1}$, Florian M. Schenk ${ }^{1}$, Alexander Gogos ${ }^{2,3}$ (D) and Sotiris E. Pratsinis $1, * \mathbb{D}$ \\ 1 Particle Technology Laboratory, Department of Mechanical and Process Engineering, Institute of Energy and \\ Process Engineering, ETH Zurich, Sonneggstrasse 3, CH-8092 Zurich, Switzerland; \\ gschwend@ptl.mavt.ethz.ch (P.M.G.); florian.schenk@ife.ee.ethz.ch (F.M.S.) \\ 2 Nanoparticle Systems Engineering Laboratory, Department of Mechanical and Process Engineering, \\ Institute of Energy and Process Engineering, ETH Zurich, Sonneggstrasse 3, CH-8092 Zurich, Switzerland; \\ alexander.gogos@empa.ch \\ 3 Particles-Biology Interactions, Swiss Federal Laboratories for Materials Science and Technology (Empa), \\ Department of Materials Meet Life, Lerchenfeldstrasse 5, CH-9014 St. Gallen, Switzerland \\ * Correspondence: pratsinis@ethz.ch
}

Citation: Gschwend, P.M.; Schenk, F.M.; Gogos, A.; Pratsinis, S.E. Acetone Sensing and Catalytic Conversion by Pd-Loaded $\mathrm{SnO}_{2}$. Materials 2021, 14, 5921. https:// doi.org/10.3390/ma14205921

Academic Editor: Cristian E. Simion

Received: 31 August 2021

Accepted: 5 October 2021

Published: 9 October 2021

Publisher's Note: MDPI stays neutral with regard to jurisdictional claims in published maps and institutional affiliations.

Copyright: (c) 2021 by the authors. Licensee MDPI, Basel, Switzerland. This article is an open access article distributed under the terms and conditions of the Creative Commons Attribution (CC BY) license (https:// creativecommons.org/licenses/by/ $4.0 /)$.

\begin{abstract}
Noble metal additives are widely used to improve the performance of metal oxide gas sensors, most prominently with palladium on tin oxide. Here, we photodeposit different quantities of $\mathrm{Pd}(0-3 \mathrm{~mol} \%)$ onto nanostructured $\mathrm{SnO}_{2}$ and determine their effect on sensing acetone, a critical tracer of lipolysis by breath analysis. We focus on understanding the effect of operating temperature on acetone sensing performance (sensitivity and response/recovery times) and its relationship to catalytic oxidation of acetone through a packed bed of such Pd-loaded $\mathrm{SnO}_{2}$. The addition of $\mathrm{Pd}$ can either boost or deteriorate the sensing performance, depending on its loading and operating temperature. The sensor performance is optimal at Pd loadings of less than $0.2 \mathrm{~mol} \%$ and operating temperatures of $200-262.5^{\circ} \mathrm{C}$, where acetone conversion is around $50 \%$.
\end{abstract}

Keywords: chemoresistive; metal oxide; breath sensor; n-type; nanoparticles

\section{Introduction}

Gas sensors have become ubiquitous in preventing gas explosions, poisoning, and drunk driving, as millions of sensors are sold each year [1]. Furthermore, they show increasing potential for medical diagnostics, especially as inexpensive and portable sensing devices become available [2]. In particular, chemoresistive metal oxide sensors are widespread due to their simplicity and low cost [3], among which the most prominent are made of $\mathrm{SnO}_{2}$, while Pd is the noble metal of choice as a dopant or additive [4].

In particular, the sensing mechanism of model gases such as $\mathrm{CO}$ or $\mathrm{H}_{2}$ have been studied thoroughly [5], focusing on reception (the interaction of reducing gases with the sensor surface), transduction (the resulting changes of the electronic properties of the sensing layer), and the influence of sensor morphology on sensing performance [6]. In particular, the role of noble metals has been investigated to boost sensor performance [7]. Specifically, the addition of $\mathrm{Pd}$ to $\mathrm{SnO}_{2}$ affects sensing through the spill-over mechanism (chemical sensitization) and electronic coupling (electronic sensitization). Still, even though the basic sensing principles are largely clear, the sensor design often follows an Edisonian approach.

In this regard, there are many similarities between gas sensing and heterogeneous catalysis. These two fields share similar preparation routes, characterization tools, and structure-function relations [8], yet few studies (Yamazoe et al. [7] for $\mathrm{H}_{2}$ and $\mathrm{C}_{3} \mathrm{H}_{8}$, Cabot et al. [9] for $\mathrm{CH}_{4}$, Ogel et al. [10] and Degler et al. [11] for CO) have considered both catalytic and sensing properties of chemoresistive materials. In particular, temperature effects on sensing are not always thoroughly investigated in sensor development. Often, the crystal size and composition as well as the noble metal loading are varied to optimize the performance of the sensor while operating it at a fixed temperature (typically between 300 and $400^{\circ} \mathrm{C}$ ) [12]. Only after this optimization, usually, the performance of the best 
sensor composition is evaluated at different operating temperatures, yielding the ideal one, typically close to the initial temperature [13].

The goal of this work is to systematically investigate Pd-loaded $\mathrm{SnO}_{2}$ sensors, focusing on their operating temperature, and explore synergies with the catalytic conversion of the analyte. Thus, acetone is important in breath analysis [14] and indoor air monitoring [15]. Specifically, breath acetone is a reliable marker [16] for ketogenic activity and a volatile byproduct [17] of lipolysis; therefore, it can serve to monitor the impact of diet and exercise on the human body. Here, the relationship between gas sensing and analyte conversion is investigated for better understanding and selection of the optimal sensing conditions and Pd loadings of the above sensors.

\section{Materials and Methods}

Synthesis of Sensing Particles: Pure $\mathrm{SnO}_{2}$ nanoparticles were prepared by flame spray pyrolysis [18]. As-prepared powders were annealed in air for five hours at $500{ }^{\circ} \mathrm{C}$. Palladium was then photo-deposited [19] onto pure flame-made and annealed $\mathrm{SnO}_{2}$ at concentrations of $0,0.1,0.2,0.5,1$, and $3 \mathrm{~mol} \%$ using a Pd-nitrate solution. Afterwards, the washed and dried powders were annealed again at $500{ }^{\circ} \mathrm{C}$ for $5 \mathrm{~h}$ to further stabilize them [20].

Powder characterization: The particle composition was investigated by X-ray diffraction (XRD, Bruker D2 Phaser), while the specific surface area (SSA) of powders was determined by $\mathrm{N}_{2}$ adsorption. The noble metal dispersion was determined on an Autochem II (Micromeritics) by CO-pulse chemisorption.

For electron microscopy analysis, specimens were imaged by TEM (transmission electron microscopy, Talos F200X, Super-X EDS, 4 detector configuration, FEI, Hillsboro, OR, USA) or HAADF-STEM (high-angle annular dark-field scanning transmission electron microscopy) combined with EDX (energy-dispersive x-ray) elemental mapping.

For chemical analysis, the Pd-loaded particles were reduced, followed by leaching in $\mathrm{HNO}_{3}$ at $60{ }^{\circ} \mathrm{C}$ for $4 \mathrm{~h}$. The leachate solution was analyzed by ICP-OES (inductively coupled plasma optical emission spectrometry, Varian 720-ES axial) to determine the Pd loading.

Sensor Fabrication: The Pd-containing $\mathrm{SnO}_{2}$ particles were mixed with 1,2-propanediol (Aldrich, purity $>99.5 \%$ ) to form viscous and homogeneous pastes. Sensing films were prepared by doctor-blading [18] onto $\mathrm{Al}_{2} \mathrm{O}_{3}$ sensor substrates $(15 \times 13 \times 0.8 \mathrm{~mm}$, Electronic Design Centre Case Western Reserve University, Electrode type \#103). The sensors were dried in ambient air for $4 \mathrm{~h}$ at $80^{\circ} \mathrm{C}$. No further annealing was done before sensing tests [21].

Sensor measurements: The sensors were tested as described previously [18]. In brief, $1 \mathrm{~L} / \mathrm{min}$ of synthetic air with $50 \%$ relative humidity $(\mathrm{RH})$ was admixed with acetone from calibrated gas standards. The sensor response (S) was defined as $S=R_{\text {air }} / R_{\text {analyte }}-1$, wherein $R_{\text {air }}$ and $R_{\text {analyte }}$ are the sensing film resistance in synthetic air (including $\mathrm{RH}$ ) without and with analyte, respectively. The sensor response and recovery times were defined as the times needed to reach or recover $90 \%$ of the resistance change during or after analyte exposure, respectively.

Catalytic measurements: Catalytic measurements were performed as described previously [22] with a small modification: The catalytic packed beds consisted of only $20 \mathrm{mg}$ particles in a quartz glass tube, which was placed inside a furnace, and $0.15 \mathrm{~L} / \mathrm{min}$ of the same gases flowed through that tube, as for the sensing tests. The off-gas was analyzed in real-time by a PTR-ToF-MS (proton transfer reaction time of flight mass spectrometry, IONICON, PTR-ToF-MS 1000, Innsbruck, Austria) to its outlet.

\section{Results and Discussion}

\subsection{Material Characterization}

Figure 1a shows the XRD patterns of $\mathrm{SnO}_{2}$ with 0 and $3 \mathrm{~mol} \% \mathrm{Pd}$ (patterns for all Pd loadings are shown in Figure S1a). They all exhibited the tetragonal cassiterite phase (squares). No peaks attributable to either Pd (circles) or PdO (triangles) were detected, even at the highest Pd loading, similar to FSP [18] and wet-made Pd-loaded $\mathrm{SnO}_{2}$. This 
can be attributed to small crystallite sizes, lack of crystallinity, and/or Pd content below the detection limit of XRD. The average $\mathrm{SnO}_{2}$ crystallite sizes $\left(\mathrm{d}_{\mathrm{XRD}}\right.$, inset Figure $1 \mathrm{a}$ and Figure S1b) were between $18.6 \mathrm{~nm}(0 \mathrm{~mol} \% \mathrm{Pd})$ and $16.8 \mathrm{~nm}(3 \mathrm{~mol} \% \mathrm{Pd})$, indicating a slight inhibition of $\mathrm{SnO}_{2}$ growth by Pd during their annealing. The primary particle sizes, $d_{\mathrm{BET}}$ (inset table in Figure 1a and Figure $\mathrm{S1b}$ ), are larger (around $25 \mathrm{~nm}$ ) than $\mathrm{d}_{\mathrm{XRD}}$, most likely due to necking (Figure 1c). It is noteworthy that, after the first annealing step (before photodeposition), crystal $\left(\mathrm{d}_{\mathrm{XRD}}=16 \mathrm{~nm}\right)$ and especially primary particle $\left(\mathrm{d}_{\mathrm{BET}}=19.8 \mathrm{~nm}\right)$ sizes of pure $\mathrm{SnO}_{2}$ were slightly smaller, indicating that annealing increased necking in agreement with the relevant literature [18].
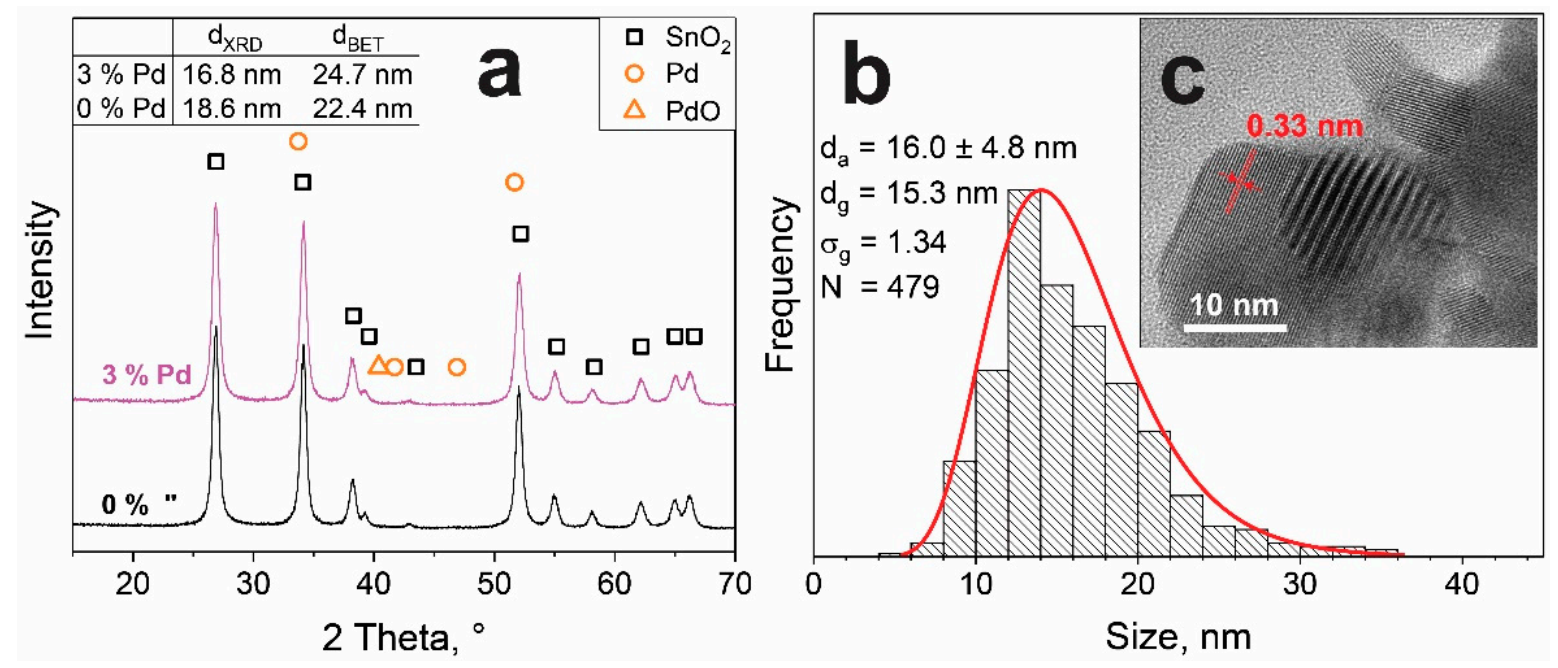

Figure 1. (a) XRD patterns of pure $(0 \%)$ and $3 \mathrm{~mol} \%$ Pd-loaded $\mathrm{SnO}_{2}$. Inset gives the crystal $\left(\mathrm{d}_{\mathrm{XRD}}\right)$ and primary particle sizes from $\mathrm{N}_{2}$-adsorption $\left(\mathrm{d}_{\mathrm{BET}}\right)$. (b) Primary particle size distribution of $3 \mathrm{~mol} \% \mathrm{Pd}$-loaded $\mathrm{SnO}_{2}$ determined by electron microscopy and fitted with a log-normal curve (red line) with the arithmetic mean $\left(\mathrm{d}_{\mathrm{a}}\right)$, geometric mean $\left(\mathrm{d}_{\mathrm{g}}\right)$, geometric standard deviation $\left(\sigma_{\mathrm{g}}\right)$, and number of counted particles $(\mathrm{N})$. (c) Representative microscopy image of $3 \mathrm{~mol} \% \mathrm{Pd}-\mathrm{loaded}$ $\mathrm{SnO}_{2}$. The (1 110$)$ lattice spacing of $\mathrm{SnO}_{2}$ is indicated as $0.33 \mathrm{~nm}$.

As a representative sample, the powder with $3 \mathrm{~mol} \% \mathrm{Pd}$ was investigated by $\mathrm{mi}-$ croscopy and its particle size distribution $\left(\mathrm{d}_{\mathrm{TEM}}\right)$ is shown in Figure $1 \mathrm{~b}$. The particles exhibit a log-normal size distribution (fitted red line), typically observed for flame-made particles. The geometric mean $\left(\mathrm{d}_{\mathrm{g}}\right)$ was $15.3 \mathrm{~nm}$, with a geometric standard deviation $\left(\sigma_{\mathrm{g}}\right)$ of 1.34, thus slightly smaller than the crystal size $\left(\mathrm{d}_{\mathrm{XRD}}\right)$ and even smaller than the primary particle size $\left(\mathrm{d}_{\mathrm{BET}}\right)$. Interestingly, the second annealing step after photodeposition hardly influenced the $\mathrm{d}_{\text {TEM }}$ size distribution of $\mathrm{SnO}_{2}$ (Figure $\mathrm{S} 2$ ) similar to $\mathrm{d}_{\mathrm{XRD}}$ (Figure 1a). The image (Figure 1c) also reveals the high crystallinity of particles, as well as some aggregation and sinter-necks, in line with the discussion above. No Pd particles could be identified by TEM, probably due to their small size or lack of contrast between Sn and Pd that have similar atomic numbers $(\mathrm{Pd}=46, \mathrm{Sn}=50)$. Furthermore, the lattice fringes have been evaluated (Figure 1c, red arrows) with the most frequent spacing of $0.335 \mathrm{~nm}$ corresponding to the (1 10 ) plane of $\mathrm{SnO}_{2}$ [18]. Additionally, fringe spacings of 0.237 and $0.265 \mathrm{~nm}$ were observed (not shown), that were indexed to (2 00$)$ and (1 01$)$ of $\mathrm{SnO}_{2}$, respectively. It is noteworthy that the latter could also originate from the $(111)$ of Pd, analogous to the XRD peak overlap at $34^{\circ}$ (Figure 1a). In sum, Pd photodeposition hardly influenced the $\mathrm{SnO}_{2}$ support, which is characterized by partially aggregated particles of high crystallinity.

Having characterized the support, the Pd configuration was investigated. Specifically, its oxidation state, loading, dispersion, and cluster size are relevant, which depend on the precursor material [23], preparation technique [24], and subsequent treatment [20]. Here, UV-assisted photochemical deposition [25] was chosen for its high dispersion of $\mathrm{Pd}$, where palladium ions are reduced to Pd metal clusters on the $\mathrm{SnO}_{2}$ surface. The deposited 
$\mathrm{Pd}$ affected the color of the powders, and their films became darker [26] for higher Pd loading (Figure 2a).
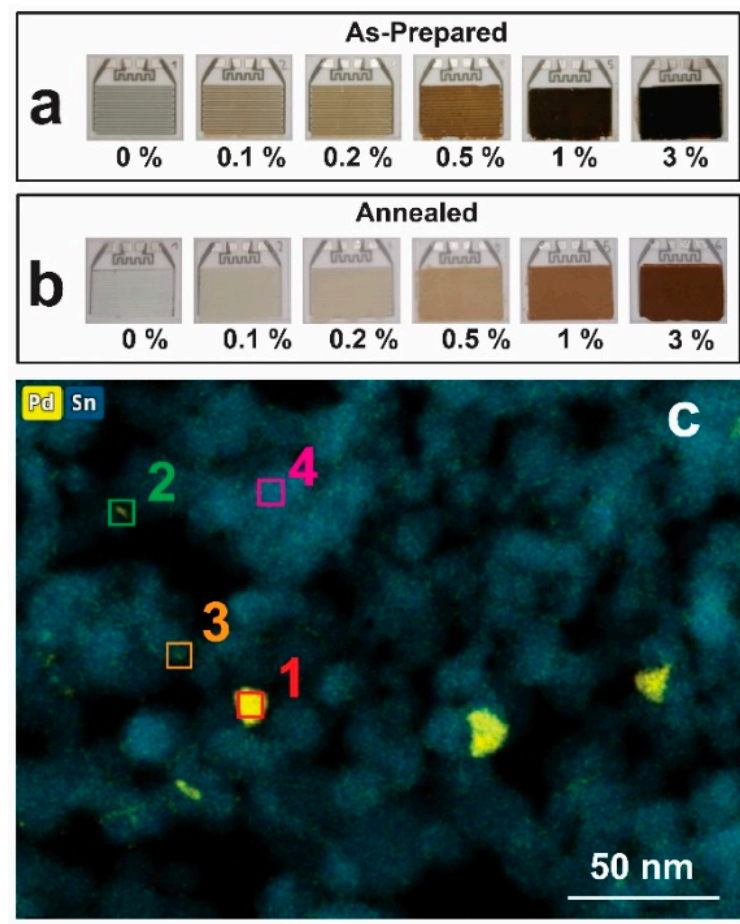

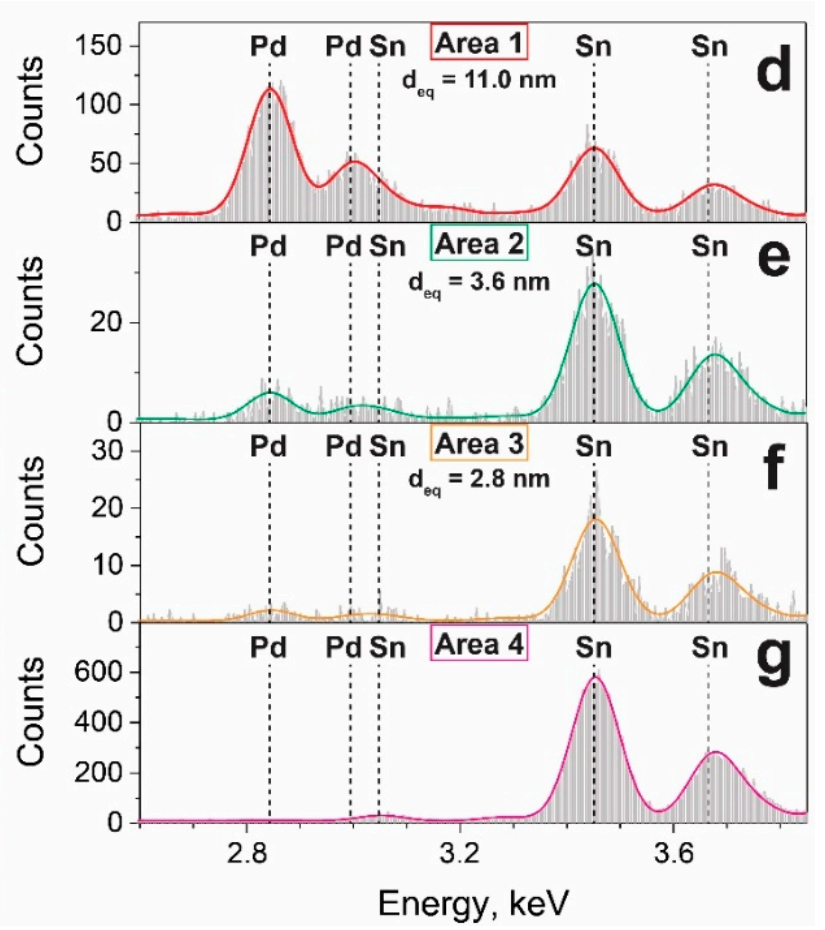

Figure 2. Sensor substrates covered with (a) as-prepared and (b) annealed films of Pd-loaded $\mathrm{SnO}_{2}$. (c) Overlayed elemental maps of Pd (yellow) and Sn (blue) of annealed $3 \mathrm{~mol} \%$ Pd-loaded $\mathrm{SnO}_{2}$. The EDX spectra of selected areas are depicted in the right panel: a large Pd-containing cluster (Area 1), spectrum in (d), a medium-sized (Area 2), spectrum in (e) and a small one (Area 3), spectrum in (f) as well as a Pd-free $\mathrm{SnO}_{2}$ region (Area 4), spectrum in (g). Colored lines represent the fitted EDX peaks.

After the first annealing, which has been reported to be crucial for stabilization [20], the appearance of the powders changed from black to brownish (Figure 2b), indicative of the formation of $\mathrm{PdO}_{x}$ [26]. Specifically, similar preparation conditions [27] led to formation of mostly $\mathrm{Pd}^{2+}(\mathrm{PdO})$ and some metal $\mathrm{Pd}$, while a minor fraction $(5 \%) \mathrm{Pd}^{3+}$ was also detected that was presumably stabilized at the Pd cluster- $\mathrm{SnO}_{2}$ interface [28]. The actual Pd loadings determined by ICP-OES were close (7-14\% relative deviation) to their nominal values (Table 1). To gather more information on $\mathrm{Pd}$ size, the $3 \mathrm{~mol} \% \mathrm{Pd}$-loaded $\mathrm{SnO}_{2}$ sample was investigated using HAADF-STEM combined with EDXS (Figure 2). Using EDXS, it was possible to visualize the Pd clusters, which were otherwise indiscernible from $\mathrm{Sn}\left(\mathrm{O}_{2}\right)$ by bright-field TEM or HAADF-STEM (Figure S3). After identification by EDXS, an area with a predominant Pd signal was subsequently imaged with HR-TEM (Figure S4): no lattice fringes were detected for these Pd-spots or Pd-containing clusters, suggesting that such clusters were mostly amorphous $\mathrm{PdO}_{\mathrm{x}}$.

Table 1. Palladium loading, dispersion, cluster size, and activation energy.

\begin{tabular}{ccccc}
\hline Nominal Loading (mol\%) & Loading By ICP-OES (mol\%) & Pd Dispersion $^{\mathbf{a}} \mathbf{( \% )}$ & Pd Size $^{\mathbf{a}} \mathbf{( n m )}$ & Activation Energy $^{\mathbf{b}} \mathbf{( k J / m o l )}$ \\
\hline 0 & - & - & - & 119.7 \\
0.1 & 0.11 & 21.6 & 5.2 & 101.8 \\
0.2 & 0.18 & 3.4 & 54.1 \\
0.5 & 0.54 & 35.8 & 3.1 & 53.8 \\
3 & 1.07 & 22.8 & 3.1 & 41.2 \\
\hline
\end{tabular}

${ }^{a}$ : Based on CO chemisorption. ${ }^{b}$ : Its determination is documented at the end of the supporting information. 
Figure 2c shows an overlay of the elemental mappings of Sn and Pd of the annealed sample, while the as-prepared is shown in Figure S5: Pd is generally well-dispersed over the Sn signal, but differently sized Pd-containing clusters were observed and analyzed through their EDX spectra (Figure $2 \mathrm{~d}-\mathrm{g}$ ). A large cluster with an area-equivalent circle diameter $\left(\mathrm{d}_{\mathrm{eq}}\right)$ of $11 \mathrm{~nm}$ diameter (Area 1, Figure 2d) showed the strongest peak in the EDX spectrum at $2.84 \mathrm{keV}$, corresponding to the Pd- $\mathrm{L}_{\alpha}$ line. A medium-sized cluster of $3.6 \mathrm{~nm}$ (Area 2, Figure 2e) exhibited the same peak, but with lower intensity than the $\mathrm{Sn}-\mathrm{L}_{\alpha}$ line at $3.443 \mathrm{keV}$. To find the lower limit of cluster size that can still be identified with confidence, the analyzed cluster size was progressively decreased. At a size $\left(\mathrm{d}_{\mathrm{eq}}\right)$ of $2.8 \mathrm{~nm}$ (Area 3 , Figure $2 \mathrm{f}$ ), the Pd signal was low, but could still be unambiguously differentiated from bare $\mathrm{SnO}_{2}$ (Area 4, Figure 2g). Therefore, the cluster size was analyzed neglecting all clusters below $3 \mathrm{~nm}$ in area-equivalent $\left(\mathrm{d}_{\mathrm{eq}}\right)$ size. Still, it should be noted that this does not rule out the presence of smaller clusters. The geometric mean cluster size was $8.6 \mathrm{~nm}$ (Figure S6a). Interestingly, before any annealing, more Pd clusters could be observed than afterwards (Figure S7), especially smaller ones, leading to a mean cluster size of only $4.6 \mathrm{~nm}$ for the as-prepared sample with $3 \mathrm{~mol} \% \mathrm{Pd}$ (Figure S6b). This indicates some Pd cluster mobility and growth during annealing. Kutukov et al. [29] prepared similar nanostructures based on FSP-made $\mathrm{SnO}_{2}$ with $1 \mathrm{wt} \% \mathrm{Pd}$ impregnated, followed by annealing at $300{ }^{\circ} \mathrm{C}$. They observed two distinct fractions of small $(<2 \mathrm{~nm})$ and large $(8-20 \mathrm{~nm})$ Pd clusters.

While visualization by elemental mapping was possible for high Pd loadings, this became increasingly difficult for lower loadings. Elemental mappings of annealed $\mathrm{SnO}_{2}$ with 1 and $0.5 \mathrm{~mol} \% \mathrm{Pd}$ are shown in Figure S8: at $1 \mathrm{~mol} \% \mathrm{Pd}$, still some Pd-clusters around $10 \mathrm{~nm}$ could be clearly distinguished (Figure S8d-f) with a diffuse Pd-signal spread over the $\mathrm{SnO}_{2}$ particles. Reducing the Pd concentration down to $0.5 \mathrm{~mol} \%$, no more large Pd clusters could be identified (Figure S8g-i), probably due to the highly homogeneous distribution of $\mathrm{Pd}$ as well as Pd-cluster sizes below $3 \mathrm{~nm}$. Similarly, a diffuse Pd signal was observed at $3 \mathrm{~mol} \%$ (Figure S8a,c), yet it was not as visible due to the presence of larger clusters. Therefore, lowering the Pd loading reduces the Pd cluster sizes, while there is a fraction of small $\mathrm{Pd}$ clusters at all $\mathrm{Pd}$ loadings.

In addition to elemental mappings, the CO-pulse chemisorption method was employed. The resulting dispersion values are given in Table 1, indicating the fraction of $\mathrm{Pd}$ available for CO-chemisorption. The dispersion values lie between 21.6 and $36.0 \%$, whereas no clear trend with Pd loading can be observed. These values can also be converted into the corresponding Pd particle sizes given in Table 1: for $3 \mathrm{~mol} \% \mathrm{Pd}$, the resulting size of $4.9 \mathrm{~nm}$ is below the observed mean value of $8.6 \mathrm{~nm}$ based on the electron microscopy analysis, which can be explained by the neglect of Pd clusters smaller than $3 \mathrm{~nm}$ in electron microscopy image counting (Figure S6, gray zones). Using the same precursors for Pd deposition with impregnation instead of photodeposition, Ma et al. [23] found a trend for increasing Pd size with higher Pd loading. Specifically, they determined a Pd size of 3.5 and $5.3 \mathrm{~nm}$ for 0.1 and $0.5 \mathrm{~mol} \% \mathrm{Pd}$ by CO chemisorption, respectively. In contrast, Takeguchi et al. [30] found a negligible influence of Pd loading (impregnation, up to $20 \mathrm{wt} \%$ ) on the Pd cluster size. The use of photodeposition could influence the growth mechanism of the Pd clusters, as Pd ions have been observed to deposit preferentially on already existing Pd clusters [25]. In summary, XRD, BET, STEM-EDXS, and $\mathrm{CO}$-chemisorption confirm the successful preparation of $\mathrm{Pd}$-decorated $\mathrm{SnO}_{2}$ nanoparticles. These particles consist of Pd clusters that are in close contact and well-dispersed on $\mathrm{Sn}$ in an oxidized state, and between 3-6 $\mathrm{nm}$ mean Pd cluster sizes by CO-chemisorption for all Pd loadings.

\subsection{Sensing}

The response to $1 \mathrm{ppm}$ acetone at 50\% relative humidity of all Pd-containing $\mathrm{SnO}_{2}$ sensors was evaluated as a function of temperature (Figure 3a). With increasing Pd loading, the maximum sensor response shifts to lower temperatures. For example, the sensor response of pure $\mathrm{SnO}_{2}$ peaks at $262.5^{\circ} \mathrm{C}$, while the sensor with $3 \% \mathrm{Pd}$ loading exhibits its 
maximum response at $200{ }^{\circ} \mathrm{C}$, the same as with 1 and $0.5 \% \mathrm{Pd}$. In terms of sensor response, all Pd-loaded samples outperform pure $\mathrm{SnO}_{2}$ at their respective ideal sensing temperature, reaching responses of up to 80 in the case of $1 \%$ Pd loading.

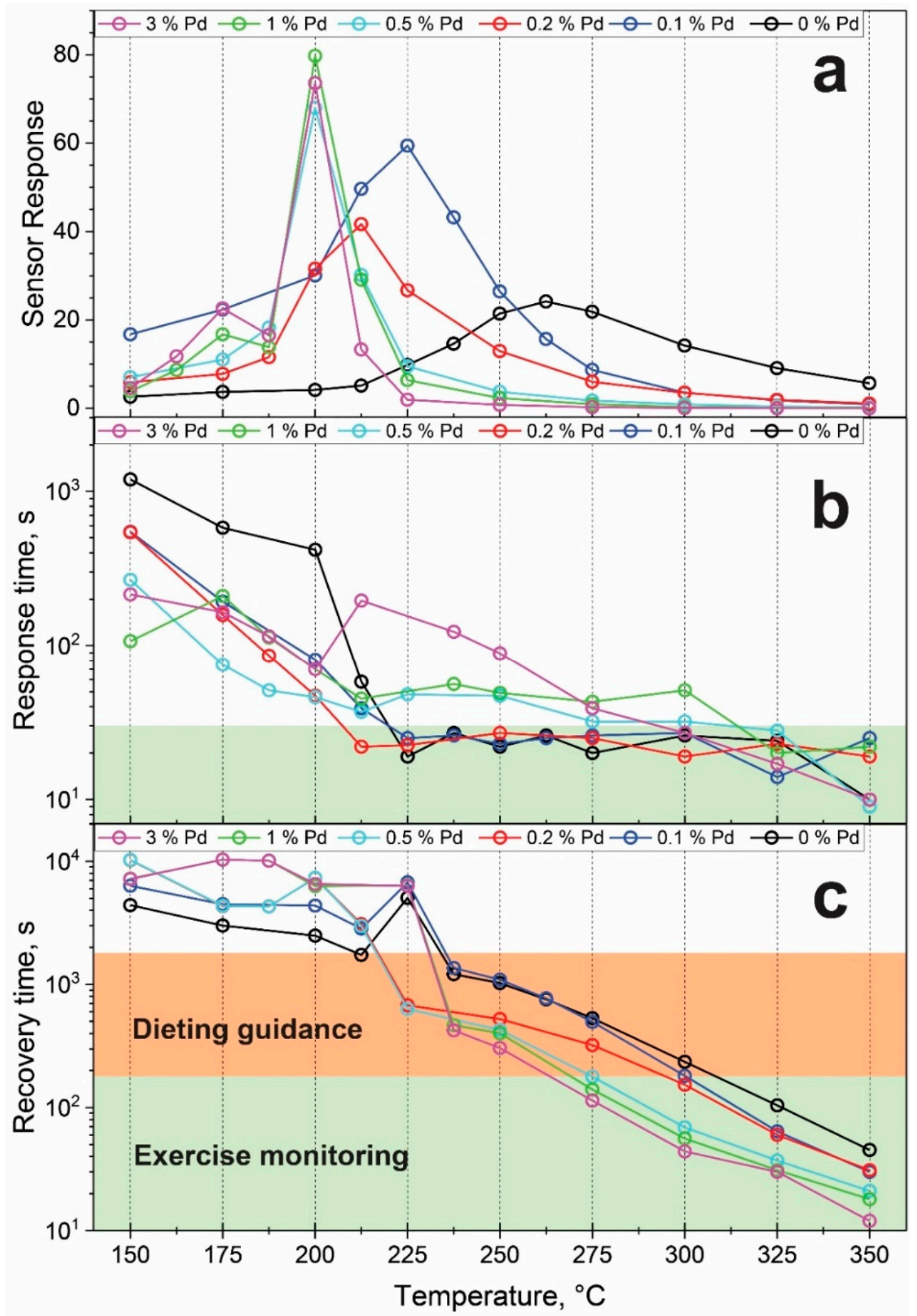

Figure 3. (a) Sensor response to $1 \mathrm{ppm}$ of acetone (50\% RH). Increasing the Pd loading shifts the sensing maximum to lower temperatures. (b) Response and (c) recovery times of these sensors.

Such a shift to lower temperatures is consistent with Korotcenkov [21] who reported a strong shift in $\mathrm{CO}(0.5 \%)$ sensing from $421^{\circ} \mathrm{C}$ in pure $\mathrm{SnO}_{2}$ to $153{ }^{\circ} \mathrm{C}$ for $\mathrm{SnO}_{2}$ with $1.1 \% \mathrm{Pd}$, with a corresponding increase in response by a factor of 2 . Additionally, Zhang et al. [31] reported such a shift in sensing $100 \mathrm{ppm} \mathrm{H}_{2}$ from $320{ }^{\circ} \mathrm{C}$ without $\mathrm{Pd}$ to $280{ }^{\circ} \mathrm{C}$ at $3 \%$ 
Pd with doubling of the sensor response. Similarly, Yuasa et al. [25] observed a shift of the optimum between unloaded and $1 \mathrm{~mol} \% \mathrm{Pd}$ in $\mathrm{H}_{2}$ sensing from 350 to $300{ }^{\circ} \mathrm{C}$ and an increase in response by a factor of 2 to $200 \mathrm{ppm}$ by increasing the Pd loading to $1 \%$. Suematsu et al. [32] found a shift from 300 to $250{ }^{\circ} \mathrm{C}$ when increasing the Pd concentration from 0 to $0.2 \%$ in sensing $50 \mathrm{ppm}$ of toluene along with an increased sensor response by a factor of 3. Lastly, Tang [33] reported a shift from 300 to $275^{\circ} \mathrm{C}$ for $1.5 \%$ Pd compared to pure $\mathrm{SnO}_{2}$ in acetone (20 ppm) sensing and an increase in response again by a factor of 2. From the above, an optimal Pd loading for maximum sensor response is in the range of $0.1-1 \%$. It is important to mention that the effect of $\mathrm{Pd}$ addition on the sensing performance is highly temperature-dependent (Figure 3a and Figure S9). For example, at $350{ }^{\circ} \mathrm{C}$, any $\mathrm{Pd}$ deteriorates the acetone sensing performance, while at $250^{\circ} \mathrm{C}$, only $0.1 \% \mathrm{Pd}$ outperforms the bare $\mathrm{SnO}_{2}$ sensor. At even lower temperatures (i.e., $200{ }^{\circ} \mathrm{C}$ ), any addition of Pd drastically improves the acetone sensing performance (Figures 3a and S9).

The mechanism for acetone sensing proceeds as follows [34]: oxygen molecules chemisorb on the $\mathrm{SnO}_{2}$ surface and are ionized to oxygen ions through the capture of free electrons from $\mathrm{SnO}_{2}$, leading to an electron depletion layer. When that surface comes into contact with a reducing gas such as acetone, it reacts with the oxygen ions on the sensing film. This reaction releases trapped electrons back to the sensing material and reduces the electron depletion layer, resulting in a drop in resistance.

Furthermore, Pd improves sensing through electronic sensitization [7], where PdO acts as an acceptor of electrons that are removed from the $\mathrm{SnO}_{2}$ surface to PdO. Thus, the electric resistance measurement in air (Figure S10) is an effective way to verify this effect [35]. Indeed, the baseline resistance increases with $\mathrm{Pd}$ loading and saturates at $0.5-1 \%$ Pd. This indicates a good electronic coupling between $\mathrm{SnO}_{2}$ and $\mathrm{PdO}_{\mathrm{x}}$ clusters [25], and consequently, changes in the composition or stoichiometry will have an impact on the electrical properties of the sensing layer.

Besides sensitivity, the response and recovery times are crucial measures of sensor performance. The response times to $1 \mathrm{ppm}$ acetone between 150 and $350{ }^{\circ} \mathrm{C}$ are shown in Figure $3 \mathrm{~b}$ for all $\mathrm{Pd}$ loadings. Above $300^{\circ} \mathrm{C}$, the response is relatively fast, between 10 and $30 \mathrm{~s}$ for all $\mathrm{Pd}$ loadings. However, for lower temperatures, the response time increases up to $1000 \mathrm{~s}$ for pure $\mathrm{SnO}_{2}$ at $150{ }^{\circ} \mathrm{C}$. The same trend was reported by Yin and Guo [36] for $\mathrm{Pd} / \mathrm{Fe}$ co-loaded $\mathrm{SnO}_{2}$ to $\mathrm{CO}$. Depending on the application, the requirements on the response time can be quite different. For example, in breath sensing, response times below $30 \mathrm{~s}$ are desired to reach a steady-state response within the duration of one buffered breath pulse [37]. This restricts already the use of operating temperatures below $212.5^{\circ} \mathrm{C}$.

Additionally, Figure $3 \mathrm{c}$ depicts the recovery time that increases at decreasing sensing temperatures similar to response time. In contrast to the response time, however, a clearer trend is observed for the recovery time as a function of Pd loading: at high temperatures $\left(>225^{\circ} \mathrm{C}\right)$, higher Pd-loadings shorten the recovery time, while at lower temperatures $\left(<200^{\circ} \mathrm{C}\right)$, this is reversed. This is likely caused by the interplay of temperature-dependent oxygen chemisorption, catalytic activity, and Pd oxidation. Still, even with high Pd loadings, the recovery time at $250^{\circ} \mathrm{C}$ is $300 \mathrm{~s}$ already. While shorter recovery times are preferred, requirements are not as stringent as for the response times and also depend on application. For example, for monitoring ketogenic diets through breath acetone measurements, samples have been taken every $3 \mathrm{~h}$ [38]. However, if breath acetone measurements are employed as a tool for personalized fat burn monitoring, a higher frequency of pulses can be desirable (e.g., $45 \mathrm{~min}$ [39] down to $5 \mathrm{~min}$ [40] between pulses). As a result, in Figure 3c, the green-shaded area represents a recovery time of $3 \mathrm{~min}$ as a rough threshold for exercise monitoring, while the orange-shaded area represents a recovery time threshold of $30 \mathrm{~min}$ that can be acceptable for monitoring dieting. Still, the present response and recovery times could be further decreased by transient response analysis [41].

Based on the above, we selected the pure $\mathrm{SnO}_{2}$ sensor operating at $325^{\circ} \mathrm{C}\left(\mathrm{t}_{\text {response }}=24 \mathrm{~s}\right.$, $\mathrm{t}_{\text {recovery }}=104 \mathrm{~s}$, response $\left.=5.8\right)$ and the $0.1 \%$ Pd-loaded sensor operating at $237.5^{\circ} \mathrm{C}$ $\left(t_{\text {response }}=26 \mathrm{~s}, t_{\text {recovery }}=1361 \mathrm{~s}\right.$, response $\left.=43.2\right)$ as the most promising acetone sensors 
requiring fast or highly sensitive sensing, respectively. The film resistance changes in response to ultralow acetone concentrations $(20-50 \mathrm{ppb})$ are shown in Figure S11. The responses to $20 \mathrm{ppb}$ could be easily distinguished with a signal-to-noise ratio (SNR) of 650 and 935 for the pure $\mathrm{SnO}_{2}\left(\right.$ at $325^{\circ} \mathrm{C}$ ) and $0.1 \%$ Pd-loaded sensor (at $237.5^{\circ} \mathrm{C}$ ), respectively. While lower concentrations were not measured, the extrapolated limits of detection (LoD) defined at a SNR $=3$ were approximately $0.05 \mathrm{ppb}$ for both sensors.

The performance of our sensors was compared to literature in terms of sensitivity, response/recovery times, and $\mathrm{LoD}$ for Pd-loaded $\mathrm{SnO}_{2}$ (Table 2) and other material compositions (Table S1) acetone sensors. Table S2 details the precise origin of all literature entries of Table 2. The reported operating temperatures range from 250 to $400{ }^{\circ} \mathrm{C}$, with one even at room temperature [34]. Looking at the sensor response, our sensors perform well, yet are outperformed in terms of response/recovery times when operated at lower temperatures. This can be attributed to slower diffusion and reaction kinetics. It should be noted that these times are not only influenced by Pd loading and temperature but also by film morphology (sometimes called "utility ratio" [42]). In summary, choosing the "best" sensor strongly depends on the targeted application and is always a compromise.

\subsection{Catalytic Conversion of Acetone by Packed Beds of Pd-Loaded $\mathrm{SnO}_{2}$ Particles}

The conversion of $1 \mathrm{ppm}$ acetone in air at $50 \%$ relative humidity was investigated as a function of temperature by off-gas analysis with PTR-ToF-MS using packed beds of the sensing particles (Figure 4a). With bare $\mathrm{SnO}_{2}$, the conversion of acetone starts at $200{ }^{\circ} \mathrm{C}$ and reaches $100 \%$ at $300{ }^{\circ} \mathrm{C}$. Increasing the Pd loading systematically shifts the acetone conversion to lower temperatures.

To quantitatively assess the catalytic activity, the activation energies were calculated based on the reaction rates at the low conversion range, as described in the supporting information and Figure S12. The activation energies (Table 1) decrease with increasing Pd loading, from $119.7 \mathrm{~kJ} / \mathrm{mol}$ for bare $\mathrm{SnO}_{2}$ to a minimum of $41.2 \mathrm{~kJ} / \mathrm{mol}$ at $1 \% \mathrm{Pd}$. Comparable values have been obtained for catalytic combustion of acetone over $\mathrm{Cu}_{0.13} \mathrm{Ce}_{0.87} \mathrm{O}_{\mathrm{y}}$ $(97 \mathrm{~kJ} / \mathrm{mol})$ [43] and $3 \mathrm{wt} \% \mathrm{MnO}_{\mathrm{x}}$ on $\mathrm{SiO}_{2}(34 \mathrm{~kJ} / \mathrm{mol})$ [44]. Thus, the addition of $\mathrm{Pd}$ effectively lowers the activation barrier in acetone oxidation.

Table 2. Comparison of reported $\mathrm{Pd}-\mathrm{SnO}_{2}$ sensors for acetone detection with their key performance indicators.

\begin{tabular}{|c|c|c|c|c|c|c|c|c|}
\hline Material & $\begin{array}{l}\text { Operating } \\
\text { Temp. } \\
{\left[{ }^{\circ} \mathrm{C}\right]}\end{array}$ & $\begin{array}{c}\text { Relative } \\
\text { Humidity } \\
{[\%]}\end{array}$ & $\begin{array}{l}\text { Response } \\
\text { a (Conc. in } \\
\text { ppm) }\end{array}$ & $\begin{array}{c}\text { Equiv. } \\
\text { Response } \\
\text { at } 1 \text { ppm }^{b}\end{array}$ & $\begin{array}{l}\text { LOD } \\
{[\mathrm{ppm}]}\end{array}$ & $\begin{array}{l}\text { Response } \\
\text { Time }^{c}[s]\end{array}$ & $\begin{array}{l}\text { Recovery } \\
\text { Time }^{\mathrm{c}}[\mathrm{s}]\end{array}$ & Reference \\
\hline $\mathrm{Pd}-\mathrm{SnO}_{2}$ & $300{ }^{\circ} \mathrm{C}$ & $\begin{array}{l}\text { Yes, but } \\
\text { not } \\
\text { specified }\end{array}$ & $78(25)$ & 23.5 & $2^{25^{*}}$ & n.a. & n.a. & $\begin{array}{l}\text { Epifani et al. } \\
\text { [45] (2008) }\end{array}$ \\
\hline $\begin{array}{l}\text { Pd-loaded flower-like } \\
\qquad \mathrm{SnO}_{2}\end{array}$ & $250{ }^{\circ} \mathrm{C}$ & No R.H. & $10(10)$ & 1 & 10 * & 11 (10 ppm) & 30 (10 ppm) & $\begin{array}{l}\text { Tian et al. } \\
\text { [46] (2014) }\end{array}$ \\
\hline Pd-SnO 2 organized & $\mathrm{RT}$ & No R.H. & $1.8(10)$ & 0.18 & 10 * & 13 & 15 & $\begin{array}{l}\text { Shao et al. } \\
\text { [34] (2015) }\end{array}$ \\
\hline $\mathrm{Pd}-\mathrm{SnO}_{2}$ nanofibers & 275 & No R.H. & $3(1)$ & 3 & $1 *$ & 20 & 40 & $\begin{array}{l}\text { Tang et al. } \\
\text { [33] (2015) }\end{array}$ \\
\hline $\begin{array}{c}\text { Pd-loaded } \mathrm{SnO}_{2} \\
\text { ultrathin } \\
\text { nanorod-assembled } \\
\text { hollow microspheres }\end{array}$ & 230 & No R.H. & $10.6(20)$ & 0.5 & n.a. & n.a. & n.a. & $\begin{array}{l}\text { Zhang et al. } \\
\text { [47] (2017) }\end{array}$ \\
\hline PdO@ZnO-SnO 2 NT & 400 & 95 & $4.1(1)$ & 4.1 & $\begin{array}{c}0.1^{*} \\
0.01^{\dagger}\end{array}$ & 19.6 & 64 & $\begin{array}{l}\text { Koo et al. } \\
\text { [48] (2017) }\end{array}$ \\
\hline $\mathrm{PdAu}-\mathrm{SnO}_{2}$ nanosheets & 250 & $40-70 \%$ & $2.7(1)$ & 2.7 & $0.0^{*} 5^{\dagger}$ & 5 & 4 & $\begin{array}{l}\text { Li et al. [49] } \\
\text { (2019) }\end{array}$ \\
\hline Pd-doped $\mathrm{SnO}_{2}$ & 350 & 50 & $7(1)$ & 7 & $0.005^{*}+$ & $60(50 \mathrm{ppb})$ & $138(50 \mathrm{ppb})$ & $\begin{array}{l}\text { Pineau et al. } \\
\text { [18] (2020) }\end{array}$ \\
\hline $\mathrm{SnO}_{2}$ & 325 & 50 & $5.8(1)$ & 5.8 & $\begin{array}{c}0.020^{*} \\
0.00005^{\dagger}\end{array}$ & 24 & 104 & This work \\
\hline $0.1 \%$ Pd-loaded $\mathrm{SnO}_{2}$ & 237.5 & 50 & $43.2(1)$ & 43.2 & $\begin{array}{c}0.020 * \\
0.00005^{\dagger}\end{array}$ & 26 & 1361 & This work \\
\hline
\end{tabular}

a: Responses were converted to the definition used in this manuscript. b: If not available, response was linearly extrapolated.

c: Concentration was 1 ppm if not stated otherwise. + : LOD calculated/estimated. *: Lowest measured concentration. 

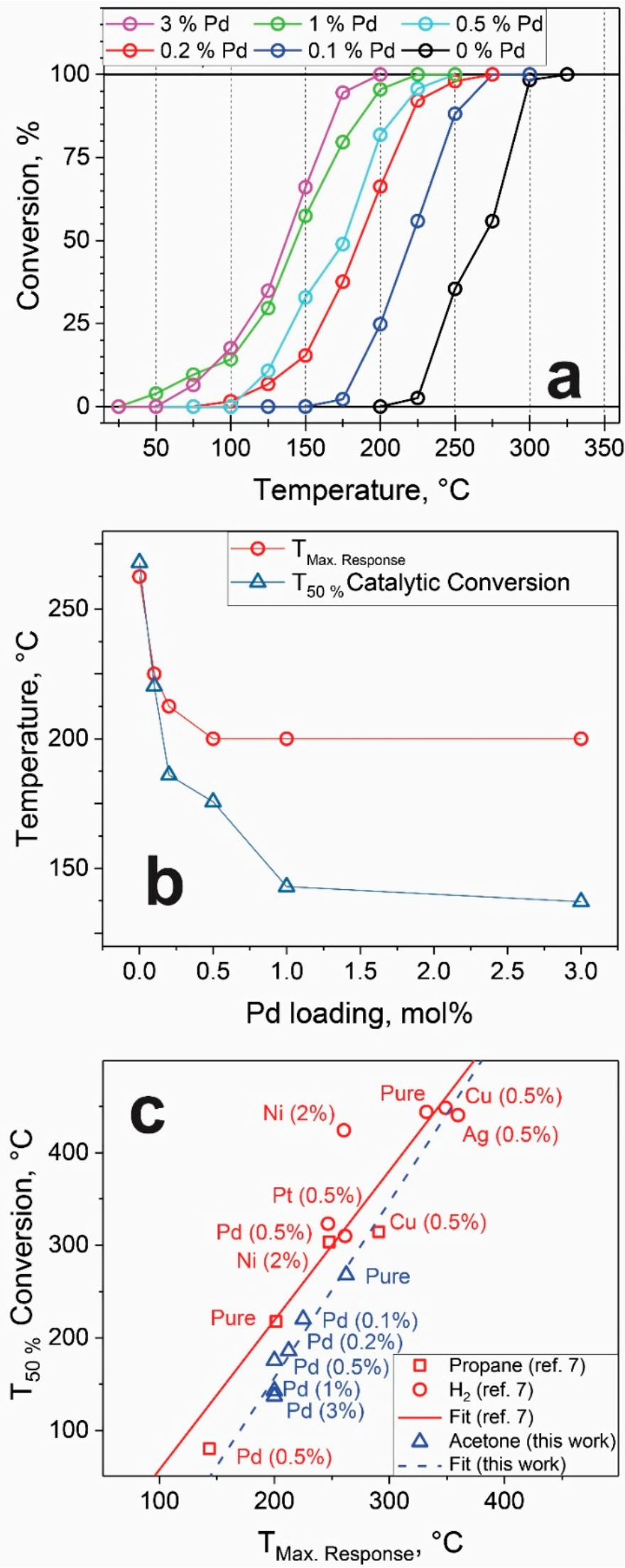

Figure 4. (a) Conversion of 1 ppm acetone; (b) Temperature of max. response and 50\% catalytic conversion as a function of Pd loading; (c) Comparison of $\mathrm{T}_{50 \%}$ conversion and $\mathrm{T}_{\text {Max. Response }}$ by [7] and this work. 
For further analysis, the temperature at $50 \%$ conversion of acetone by all Pd-loaded $\mathrm{SnO}_{2}$ packed beds is shown in Figure $4 \mathrm{~b}$ (blue triangles) as a function of Pd loading. Already, the addition of small amounts of $\mathrm{Pd}$ strongly decreases the oxidation temperature that practically levels off at about $150{ }^{\circ} \mathrm{C}$ at $1 \% \mathrm{Pd}$. Similar behavior has been observed recently [50] in catalytic oxidation of acetone over $\mathrm{Pt} / \mathrm{Al}_{2} \mathrm{O}_{3}$. However, a stronger temperature shift from 325 to almost $50{ }^{\circ} \mathrm{C}$ was observed, and leveling off started with a Pt loading of $3 \%$. Such beneficial effects of Pd loading have been attributed to chemical sensitization [51]; palladium is a much better catalyst for activation of the dissociation of molecular oxygen than $\mathrm{SnO}_{2}$ [13]. Thus, $\mathrm{PdO}_{\mathrm{x}}$ clusters form sites of dissociative adsorption, where reaction products (oxygen radicals) diffuse to the metal oxide support surface (spill-over effect) [52].

Figure $4 \mathrm{~b}$ compares also the temperature for $50 \%$ acetone conversion $\left(\mathrm{T}_{50 \%}\right)$ of $\mathrm{Pd}$ loaded $\mathrm{SnO}_{2}$ (triangles) to their optimal sensing temperatures (circles). Both are quite similar, with a steep drop at low Pd loadings and leveling off at higher ones. Similarly, Yamazoe et al. [7] investigated both the catalytic and sensing properties of different metalloaded $\mathrm{SnO}_{2}$ towards propane $(0.2 \%)$ and hydrogen $(0.8 \%)$, shown in Figure $4 \mathrm{c}$ as red squares and circles, respectively. They reported a correlation between ideal sensing temperature (in terms of maximum response) and $\mathrm{T}_{50 \%}$ conversion, independent of metal loading or analyte. By comparing our data (Figure 4c, blue triangles) with theirs, a similar trend is observed here for acetone. The shift of the present correlation to slightly lower conversion temperatures is probably due to different size (and/or porosity) of the catalytic bed and humidity of gas streams (0 [7] vs. 50\%) or the much lower gas concentrations [53] ( $8000 \mathrm{ppm} \mathrm{H}_{2}$ and $2000 \mathrm{ppm}$ propane vs. 1 ppm acetone).

\section{Conclusions}

Palladium-loaded $\mathrm{SnO}_{2}$ powders were prepared by photodeposition of Pd onto flamemade $\mathrm{SnO}_{2}$. The $\mathrm{SnO}_{2}$ particles were highly crystalline and not affected by the addition of $\mathrm{Pd}$. Well-dispersed $\mathrm{PdO}_{\mathrm{x}}$ clusters between 4 and $6 \mathrm{~nm}$ in diameter (and even finer) were revealed on the $\mathrm{SnO}_{2}$ surface. The optimal temperature for acetone sensitivity decreases with increasing Pd loading, while the sensor response and recovery times increase for lower temperatures. While the addition of Pd reduces these times, relatively high temperatures are still required for sensing of acetone for dieting guidance or exercise monitoring. The contribution of Pd to the sensing behavior was explained both by electronic and chemical sensitization. The complementary catalytic measurements revealed a strong correlation to the sensing temperature, where the highest responses were found close to $50 \%$ acetone conversion, representing a balance between signal reception and transduction.

Supplementary Materials: The following are available online at https: / www.mdpi.com/article/ 10.3390/ma14205921/s1, More detailed experimental section, Figure S1: XRD patterns, crystallite and primary particle sizes, Figure S2: Particle size distribution from electron microscopy, Figure S3: HAADF-STEM images with Pd-mapping, Figure S4: HAADF-STEM images with Pd elemental mapping and EDX-spectra, Figure S5: Elemental maps and EDX-spectra of as-prepared Pd-loaded $\mathrm{SnO}_{2}$, Figure S6: Pd cluster size distribution, Figure S7: Microscopy images with Pd and Sn elemental mappings before and after annealing, Figure S8: Elemental maps with different Pd contents, Figure S9: Sensing responses at different temperatures, Figure S10: Baseline resistances, Figure S11: Film resistance in response to low concentration acetone pulses, Figure S12: Acetone conversion fitting, Table S1: Comparison of reported acetone sensors not based on $\mathrm{Pd}-\mathrm{SnO}_{2}$. Table S2: Table 2 with detailed origin of data.

Author Contributions: P.M.G. contributed to the study design, performed experiments, analyzed data, and drafted the manuscript. F.M.S. performed particle synthesis and assisted with sensor measurements. A.G. performed electron microscopy and elemental analysis. S.E.P. conceived and supervised the study and edited the manuscript. All authors contributed to the manuscript writing and have approved the final version of the manuscript. 
Funding: This research was mainly supported by the Particle Technology Laboratory, and in part by the Swiss National Science Foundation (grant nos. 182668 and 183298).

Institutional Review Board Statement: Not applicable.

Informed Consent Statement: Not applicable.

Data Availability Statement: Data are contained within the article or supplementary material.

Acknowledgments: We thank Christoph Müller for access to CO-chemisorption equipment and Hui Zhou as well as David Niedbalka (all ETH Zurich) for performing these experiments. Furthermore, we thank the Scientific Center for Optical and Electron Microscopy (ScopeM) of ETH Zurich for access to their microscopes.

Conflicts of Interest: The authors declare no conflict of interest.

\section{References}

1. Kemmler, J.A.; Pokhrel, S.; Mädler, L.; Weimar, U.; Bârsan, N. Flame spray pyrolysis for sensing at the nanoscale. Nanotechnology 2013, 24, 442001. [CrossRef] [PubMed]

2. Güntner, A.T.; Abegg, S.; Konigstein, K.; Gerber, P.A.; Schmidt-Trucksäss, A.; Pratsinis, S.E. Breath sensors for health monitoring. ACS Sens. 2019, 4, 268-280. [CrossRef]

3. Righettoni, M.; Amann, A.; Pratsinis, S.E. Breath analysis by nanostructured metal oxides as chemo-resistive gas sensors. Mater. Today 2015, 18, 163-171. [CrossRef]

4. Malik, R.; Tomer, V.K.; Mishra, Y.K.; Lin, L. Functional gas sensing nanomaterials: A panoramic view. Appl. Phys. Rev. 2020, 7, 021301. [CrossRef]

5. Yamazoe, N.; Sakai, G.; Shimanoe, K. Oxide semiconductor gas sensors. Catal. Surv. Asia 2003, 7, 63-75. [CrossRef]

6. Bârsan, N.; Weimar, U. Conduction model of metal oxide gas sensors. J. Electroceram. 2001, 7, 143-167. [CrossRef]

7. Yamazoe, N.; Kurokawa, Y.; Seiyama, T. Effects of additives on semiconductor gas sensors. Sens. Actuators 1983, 4, 283-289. [CrossRef]

8. Müller, S.A.; Degler, D.; Feldmann, C.; Türk, M.; Moos, R.; Fink, K.; Studt, F.; Gerthsen, D.; Bârsan, N.; Grunwaldt, J.-D. Exploiting synergies in catalysis and gas sensing using noble metal-loaded oxide composites. Chemcatchem 2018, 10, 864-880. [CrossRef]

9. Cabot, A.; Vilà, A.; Morante, J.R. Analysis of the catalytic activity and electrical characteristics of different modified $\mathrm{SnO}_{2}$ layers for gas sensors. Sens. Actuators B Chem. 2002, 84, 12-20. [CrossRef]

10. Ogel, E.; Müller, S.A.; Sackmann, A.; Gyger, F.; Bockstaller, P.; Brose, E.; Casapu, M.; Schöttner, L.; Gerthsen, D.; Feldmann, C.; et al. Comparison of the catalytic performance and carbon monoxide sensing behavior of $\mathrm{Pd}_{-} \mathrm{SnO}_{2}$ Core@Shell nanocomposites. Chemcatchem 2017, 9, 407-413. [CrossRef]

11. Degler, D.; Müller, S.A.; Doronkin, D.E.; Wang, D.; Grunwaldt, J.-D.; Weimar, U.; Barsan, N. Platinum loaded tin dioxide: A model system for unravelling the interplay between heterogeneous catalysis and gas sensing. J. Mater. Chem A 2018, 6, 2034-2046. [CrossRef]

12. Tofighi, G.; Degler, D.; Junker, B.; Müller, S.; Lichtenberg, H.; Wang, W.; Weimar, U.; Barsan, N.; Grunwaldt, J.-D. Microfluidically synthesized $\mathrm{Au}, \mathrm{Pd}$ and $\mathrm{AuPd}$ nanoparticles supported on $\mathrm{SnO}_{2}$ for gas sensing applications. Sens. Actuators B Chem. 2019, 292, 48-56. [CrossRef]

13. Kolmakov, A.; Klenov, D.O.; Lilach, Y.; Stemmer, S.; Moskovits, M. Enhanced gas sensing by individual $\mathrm{SnO}_{2}$ nanowires and nanobelts functionalized with Pd catalyst particles. Nano Lett. 2005, 5, 667-673. [CrossRef]

14. Judilla, A.M.; Nair, R.; Bruzek, J.A.; Kundu, S.K. Breath acetone analyzer: Diagnostic tool to monitor dietary fat loss. Clin. Chem. 1993, 39, 87-92.

15. Forsyth, C.; Broder, M.W. Toxicological review of acetone. In Support of Summary Information on the Integrated Risk Information System (IRIS); United States Environmental Protection Agency: Washington, DC, USA, 2017.

16. Freund, G. The calorie deficiency hypothesis of ketogenesis tested in man. Metabolism 1965, 14, 985-990. [CrossRef]

17. Kalapos, M.P. On the mammalian acetone metabolism: From chemistry to clinical implications. Biochim. Biophys. Acta (BBA)-Gen. Subj. 2003, 1621, 122-139. [CrossRef]

18. Pineau, N.J.; Keller, S.D.; Güntner, A.T.; Pratsinis, S.E. Palladium embedded in $\mathrm{SnO}_{2}$ enhances the sensitivity of flame-made chemoresistive gas sensors. Microchim. Acta 2020, 187, 1-9. [CrossRef] [PubMed]

19. Fujiwara, K.; Muller, U.; Pratsinis, S.E. Pd subnano-clusters on $\mathrm{TiO}_{2}$ for solar-light removal of NO. ACS Catal. 2016, 6, 1887-1893. [CrossRef]

20. Korotcenkov, G. Gas response control through structural and chemical modification of metal oxide films: State of the art and approaches. Sens. Actuators B Chem. 2005, 107, 209-232. [CrossRef]

21. Korotcenkov, G.; Brinzari, V.; Boris, Y.; Ivanov, M.; Schwank, J.; Morante, J. Influence of surface Pd doping on gas sensing characteristics of $\mathrm{SnO}_{2}$ thin films deposited by spray pirolysis. Thin Solid Film. 2003, 436, 119-126. [CrossRef]

22. Güntner, A.T.; Weber, I.C.; Pratsinis, S.E. Catalytic filter for continuous and selective ethanol removal prior to gas sensing. ACS Sens. 2020, 5, 1058-1067. [CrossRef] [PubMed] 
23. Ma, N.; Suematsu, K.; Yuasa, M.; Shimanoe, K. Pd size effect on the gas sensing properties of Pd-loaded $\mathrm{SnO}_{2}$ in humid Atmosphere. ACS Appl. Mater. Inter. 2015, 7, 15618-15625. [CrossRef] [PubMed]

24. Amalric-Popescu, D.; Bozon-Verduraz, F. $\mathrm{SnO}_{2}$-supported palladium catalysts: Activity in deNOx at low temperature. Catal. Lett. 2000, 64, 125-128. [CrossRef]

25. Yuasa, M.; Kida, T.; Shimanoe, K. Preparation of a stable sol suspension of Pd-loaded $\mathrm{SnO}_{2}$ nanocrystals by a photochemical deposition method for highly sensitive semiconductor gas sensors. ACS Appl. Mater. Inter. 2012, 4, 4231-4236. [CrossRef] [PubMed]

26. Avila, J.I.; Matelon, R.J.; Trabol, R.; Favre, M.; Lederman, D.; Volkmann, U.G.; Cabrera, A.L. Optical properties of Pd thin films exposed to hydrogen studied by transmittance and reflectance spectroscopy. J. Appl. Phys. 2010, 107, 023504. [CrossRef]

27. Koziej, D.; Hübner, M.; Barsan, N.; Weimar, U.; Sikora, M.; Grunwaldt, J.-D. Operando X-ray absorption spectroscopy studies on Pd-SnO 2 based sensors. Phys. Chem. Chem. Phys. 2009, 11, 8620-8625. [CrossRef]

28. Marikutsa, A.V.; Rumyantseva, M.N.; Gaskov, A.M.; Konstantinova, E.A.; Grishina, D.A.; Deygen, D.M. CO and NH 3 sensor properties and paramagnetic centers of nanocrystalline $\mathrm{SnO}_{2}$ modified by Pd and Ru. Thin Solid Film. 2011, 520, 904-908. [CrossRef]

29. Kutukov, P.; Rumyantseva, M.; Krivetskiy, V.; Filatova, D.; Batuk, M.; Hadermann, J.; Khmelevsky, N.; Aksenenko, A.; Gaskov, A. Influence of mono- and bimetallic $\mathrm{PtO}_{\mathrm{x}}, \mathrm{PdO}_{\mathrm{x}}, \mathrm{PtPdO}_{\mathrm{x}}$ clusters on $\mathrm{CO}$ sensing by $\mathrm{SnO}_{2}$ based gas sensors. Nanomaterials 2018, 8, 917. [CrossRef]

30. Takeguchi, T. Strong chemical interaction between $\mathrm{PdO}$ and $\mathrm{SnO}_{2}$ and the influence on catalytic combustion of methane. Appl. Catal. A Gen. 2003, 252, 205-214. [CrossRef]

31. Zhang, H.; Li, Z.; Liu, L.; Xu, X.; Wang, Z.; Wang, W.; Zheng, W.; Dong, B.; Wang, C. Enhancement of hydrogen monitoring properties based on $\mathrm{Pd}-\mathrm{SnO}_{2}$ composite nanofibers. Sens. Actuators B Chem. 2010, 147, 111-115. [CrossRef]

32. Suematsu, K.; Shin, Y.; Hua, Z.; Yoshida, K.; Yuasa, M.; Kida, T.; Shimanoe, K. Nanoparticle cluster gas sensor: Controlled clustering of $\mathrm{SnO}_{2}$ nanoparticles for highly sensitive toluene detection. ACS Appl. Mater. Interfaces 2014, 6, 5319-5326. [CrossRef] [PubMed]

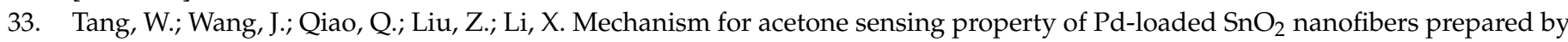
electrospinning: Fermi-level effects. J. Mater. Sci. 2015, 50, 2605-2615. [CrossRef]

34. Shao, S.; Wu, H.; Wang, S.; Hong, Q.; Koehn, R.; Wu, T.; Rao, W.-F. Highly crystalline and ordered nanoporous $\mathrm{SnO}_{2}$ thin films with enhanced acetone sensing property at room temperature. J. Mater. Chem. C 2015, 3, 10819-10829. [CrossRef]

35. Xu, C.N.; Tamaki, J.; Miura, N.; Yamazoe, N. Nature of sensitivity promotion in Pd-loaded $\mathrm{SnO}_{2}$ gas sensor. J. Electrochem. Soc. 1996, 143, L148-L150. [CrossRef]

36. Yin, X.-T.; Guo, X.-M. Selectivity and sensitivity of Pd-loaded and Fe-doped $\mathrm{SnO}_{2}$ sensor for CO detection. Sens. Actuators $B$ Chem. 2014, 200, 213-218. [CrossRef]

37. Weber, I.C.; Derron, N.; Königstein, K.; Gerber, P.A.; Güntner, A.T.; Pratsinis, S.E. Monitoring lipolysis by sensing breath acetone down to parts-per-billion. Small Sci. 2021, 1, 2100004. [CrossRef]

38. Güntner, A.T.; Kompalla, J.F.; Landis, H.; Theodore, S.J.; Geidl, B.; Sievi, N.A.; Kohler, M.; Pratsinis, S.E.; Gerber, P.A. Guiding ketogenic diet with breath acetone sensors. Sensors 2018, 18, 3655. [CrossRef]

39. Güntner, A.T.; Sievi, N.A.; Theodore, S.J.; Gulich, T.; Kohler, M.; Pratsinis, S.E. Noninvasive body fat burn monitoring from exhaled acetone with Si-doped $\mathrm{WO}_{3}$-sensing nanoparticles. Anal. Chem. 2017, 89, 10578-10584. [CrossRef] [PubMed]

40. Königstein, K.; Abegg, S.; Schorn, A.N.; Weber, I.C.; Derron, N.; Krebs, A.; Gerber, P.A.; Schmidt-Trucksäss, A.; Güntner, A.T. Breath acetone change during aerobic exercise is moderated by cardiorespiratory fitness. J. Breath Res. 2020, 15, 016006. [CrossRef]

41. Lampe, U.; Gerblinger, J.; Meixner, H. Comparison of transient response of exhaust-gas sensors based on thin films of selected metal oxides. Sens. Actuators B Chem. 1992, 7, 787-791. [CrossRef]

42. Li, X.; Lu, D.; Shao, C.; Lu, G.; Li, X.; Liu, Y. Hollow $\mathrm{CuFe}_{2} \mathrm{O}_{4} / \alpha-\mathrm{Fe}_{2} \mathrm{O}_{3}$ composite with ultrathin porous shell for acetone detection at ppb levels. Sens. Actuators B Chem. 2018, 258, 436-446. [CrossRef]

43. $\mathrm{Hu}, \mathrm{C}$. Catalytic combustion kinetics of acetone and toluene over $\mathrm{Cu}_{0.13} \mathrm{Ce}_{0.87} \mathrm{O}_{\mathrm{y}}$ catalyst. Chem. Eng. J. 2011, 168, 1185-1192 [CrossRef]

44. Reed, C.; Lee, Y.-K.; Oyama, S.T. Structure and oxidation state of silica-supported manganese oxide catalysts and reactivity for acetone oxidation with ozone. J. Phys. Chem. B 2006, 110, 4207-4216. [CrossRef] [PubMed]

45. Epifani, M.; Arbiol, J.; Pellicer, E.; Comini, E.; Siciliano, P.; Faglia, G.; Morante, J.R. Synthesis and gas-sensing properties of Pd-Doped $\mathrm{SnO}_{2}$ Nanocrystals. A case study of a general methodology for doping metal oxide nanocrystals. Cryst. Growth Des. 2008, 8, 1774-1778. [CrossRef]

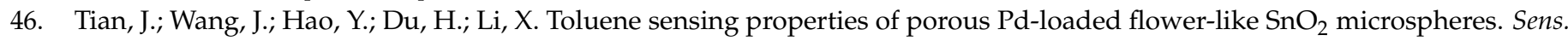
Actuators B Chem. 2014, 202, 795-802. [CrossRef]

47. Zhang, K.; Yang, X.; Wang, Y.; Bing, Y.; Qiao, L.; Liang, Z.; Yu, S.; Zeng, Y.; Zheng, W. Pd-loaded SnO 2 ultrathin nanorod-assembled hollow microspheres with the significant improvement for toluene detection. Sens. Actuators B Chem. 2017, 243, 465-474. [CrossRef]

48. Koo, W.-T.; Jang, J.-S.; Choi, S.-J.; Cho, H.-J.; Kim, I.-D. Metal-organic framework templated catalysts: Dual sensitization of $\mathrm{PdO}-\mathrm{ZnO}$ composite on hollow $\mathrm{SnO}_{2}$ nanotubes for selective acetone sensors. ACS Appl. Mater. Interfaces 2017, 9, 18069-18077. [CrossRef] 
49. Li, G.; Cheng, Z.; Xiang, Q.; Yan, L.; Wang, X.; Xu, J. Bimetal PdAu decorated $\mathrm{SnO}_{2}$ nanosheets based gas sensor with temperaturedependent dual selectivity for detecting formaldehyde and acetone. Sens. Actuators B Chem. 2019, 283, 590-601. [CrossRef]

50. Weber, I.C.; Wang, C.-T.; Güntner, A.T. Room-temperature catalyst enables selective acetone sensing. Materials $2021,14,1839$. [CrossRef]

51. Batzill, M.; Diebold, U. The surface and materials science of tin oxide. Prog. Surf. Sci. 2005, 79, 47-154. [CrossRef]

52. Marikutsa, A.V.; Rumyantseva, M.N.; Frolov, D.D.; Morozov, I.V.; Boltalin, A.I.; Fedorova, A.A.; Petukhov, I.A.; Yashina, L.V.; Konstantinova, E.A.; Sadovskaya, E.M.; et al. Role of $\mathrm{PdO}_{\mathrm{x}}$ and $\mathrm{RuO}_{\mathrm{y}}$ clusters in oxygen exchange between nanocrystalline tin dioxide and the gas phase. J. Phys. Chem. C 2013, 117, 23858-23867. [CrossRef]

53. Hu, C.; Zhu, Q.; Jiang, Z.; Chen, L.; Wu, R. Catalytic combustion of dilute acetone over Cu-doped ceria catalysts. Chem. Eng. J. 2009, 152, 583-590. [CrossRef] 